\title{
O negro, o índio, a cidade e o esquecimento: a cartografia dos vencidos como uma possibilidade de leitura do território
}

\author{
The black, the native Brazilians, the city and the oblivion: the cartography of the defeated as \\ a possibility of reading the territory
}

\author{
Maria Ester Ferreira da Silva Viegas \\ Doutora em Geografia, com Pós-Doc pela Universidade de Aveiro-PT \\ Pesquisadora Associada do GOVCOPP, DCSPT, University of Aveiro-PT \\ Professora Associada no Campus Arapiraca, UFAL \\ mestersilva@palmeira.ufal.br
}

\begin{abstract}
Resumo
Um dos aspectos importantes da crítica da cartografia geo-histórica é que ela seguiu um curso de limpeza étnica. A cartografia é um "discurso de poder", cujo silêncio em relação às populações minoritárias ou dominadas são recorrentes. Os mapas utilizados nas escolas, principalmente nas áreas rurais, não retratam os povos tradicionais: indígenas, ribeirinhos, caiçaras, quilombolas, pescadores, pequenos agricultores rurais etc. Uma abordagem menos eurocêntrica da cartografia histórica é discutida pós-1945, mas não consegue chegar até às populações locais. Os povos se deslocam, erguem cidades, mas não são visibilizados cartograficamente nelas. É oportuno apontar estas invisibilidades dos povos tradicionais, a exemplo dos quilombolas da Tabacaria e dos índios Xucurus-Kariris, ambos localizados na cidade de Palmeira dos Índios-Alagoas. A negação da cartografia dos povos indígenas e quilombolas nas cidades onde coexistem é a negação da própria história da cidade. Urge que se produza e divulgue uma cartografia social dos conflitos pela terra, das territorialidades indígenas e quilombolas que emergem cotidianamente, das lutas dos diferentes povos em todo território alagoano. Compreende-se que, para retirar os povos tradicionais dessa invisibilidade jurídica, cartográfica e política, é necessário que os pesquisadores estejam atentos, apostem numa outra cartografia: a cartografia social, onde as populações locais sejam visibilizadas, localizadas e discutidas dentro do planejamento da cidade, nos conteúdos curriculares, na vida da cidade, construindo uma geografia que os tire da condição de "esquecimento" no qual foram encarcerados pelos geo-historiadores da escrita estamental.
\end{abstract}

Palavras-chave: Currículo; Povos Tradicionais; Cartografia Social; Cidade; Geografia dos Vencidos.

\begin{abstract}
One of the critical aspects of the geo-historical cartography's criticism is that it has followed a course of ethnic clean-up. The cartography is a "discourse of power", where the silence concerning the minorities or oppressed populations is recurrent. The maps used in the schools, especially in rural areas, do not depict the traditional people: indigenous, Ribeirinhos, Caiçaras, maroons, fishers, small farmers, and so on. A less Eurocentric approach of the historical cartography was discussed after 1945 , but it could not reach the local population. The people move, build up cities, but they are not cartographically visualized in them. It is well-timed to point out these invisibilities from the traditional people, for instance, the maroons from Tabacaria and the indigenous people XucurusKariris in the city of Palmeira dos Índios in the federal state of Alagoas. The negation of the cartography from the indigenous people and the maroons in the cities where they co-exist is the negation of the history of the city. It is necessary to produce and to spread social cartography about the territorial conflicts, about the indigenous and maroons' territorial matters which come up daily, about the fight from different people in all the territory on the federal state of Alagoas. We understand that is necessary that researchers are aware of this issue to finish this legal, cartographical, and political invisibility of the traditional people and they invest their efforts in
\end{abstract}


another cartography: a social cartography, where the local population is visible, localized and discussed inside the city planning, in the curricular content, in the life of the city, building geography which remove the "oblivion" condition given by geo-historians of the three estates' writing.

Keywords: Curriculum; Traditional People; Social Cartography; City; The Geography of the Defeated.

\section{INTRODUÇÃO}

O presente texto tem como objetivo discutir a questão dos territórios sociais e suas cartografias em Palmeira dos Índios, entendendo que por meio da Cartografia Social (CS) poderemos tratar de uma problemática que envolve questões de ordem cultural, política e econômica. É de fundamental importância a reflexão do lugar dos povos negros e indígenas, no tempo histórico das contradições da valorização do espaço que se caracteriza na alienação e reificação do valor capitalista da apropriação dos territórios indígenas e quilombolas no processo de formação territorial do Brasil, com recorte especifico nas construções das cidades, principalmente as que são de origem remota, como é o caso da cidade de Palmeira dos Índios.

Com as recentes discussões no Brasil nas diferentes áreas do conhecimento sobre a dinâmica da colonização, as relações culturais em uma situação de contato, sobre a identidade étnica, a territorialização etc., como também com as novas abordagens pelos estudos de História e Geografia influenciados pelos debates antropológicos, está sendo possível repensar a ideia atribuída aos indígenas e negros como “povos derrotados”, passivos, subjugados, que passaram a ser vistos como sujeitos/agentes ativos no processo colonial, num contexto de dominação/imposição cultural.

$\mathrm{O}$ que aconteceu com os povos indígenas e quilombolas em Alagoas? O que se conhece dos indígenas em Alagoas no século XIX? E sobre os povos indígenas no sertão alagoano? Qual a presença indígena e quilombola na geo-história recente de Alagoas, mais particularmente na cidade de Palmeira dos Índios? São questões que desafiam a pesquisa, a reflexão histórica e geográfica as quais pretendemos contribuir para o início de uma discussão sobre o assunto, com o recorte no âmbito da cartografia social a partir de algumas ideias gerais, nos limites do espaço que permite esse texto. Para tanto iremos nos utilizar de algumas diretrizes conceituais utilizadas pelos estudiosos das questões sociais, dentre elas a cartografia social e a categoria do "esquecimento". Sob esses dois parâmetros, iremos iniciar uma escrita sobre a invisibilidade cartográfica dos povos tradicionais na cartografia formal (convencional) na cidade de Palmeira dos Índios. É evidente que tal condição extrapola o município de Palmeira dos Índios, pois é consequência de uma escrita estamental e arbitrária, solidificada durante anos de governo com uma forte visão eurocêntrica e apoiados por uma cartografia histórica não menos arbitrária, sendo "um discurso de poder", 
silenciando sobre as populações minoritárias ou dominadas. Nesse texto buscamos outras geografias silenciadas por uma historiografia burguesa que se apoiou em uma concepção de tempo-espaço homogêneo, onde não foi possível identificar outras "histórias" e outras "geografias", capaz de refletir os sofrimentos e as dores de uma parcela da sociedade relegada ao silêncio e ao esquecimento.

\section{O ESQUECIMENTO" COMO CATEGORIA}

Na obra “A Utopia Armada”, Dirceu Lindoso aponta para um cárcere textual, produzido pelo discurso historiográfico que enclausurou as insurreições cabanas, fato este que Lindoso chamou de "esquecimento". Não um esquecimento propriamente dito, mas sim um esquecimento fruto de um discurso depreciativo. E isto ele percebeu por meio da negatividade como os cabanos são tratados em obras como o "Opúsculo da Descrição Geográfica” de Antônio Joaquim de Moura e na "Geografia Alagoana" de Tomaz do Bonfim Espíndola. Nessas obras os cabanos são apontados como "mantilha de feras humanas mui bem armadas" e de "cabanada Selvagem", respectivamente.

Esse conceito pejorativo que Lindoso denuncia nas obras de Tomaz Espíndola e Antônio Joaquim de Moura são conceitos que influenciam toda uma geração de intelectuais alagoanos no trato com o negro. Isto está muito claro no trabalho de Alfredo Brandão, que embora temporalmente separada em mais de um século das obras anteriormente citadas, reafirma esse discurso encerrado dentro de um cárcere textual em que o negro apenas pode ser visto por esse foco de análise, e daí não se estranhar que ele seja tratado como o "bárbaro", o "selvagem", "uma mantilha de feras". Há um esvaziamento de sentido por parte desse tipo de discurso que, não esquecendo de mencionar esse personagem da história, menciona-o dentro dos limites tradicionalmente estabelecidos pelo discurso oficial, provocando o que Lindoso chama de "empobrecimento compulsório". Para os cabanos: "O "esquecimento" significou a reestruturação, por meios violentos, da antiga hierarquia social que o sistema de colonização portuguesa estabeleceu na sua colônia da América (...) [bem como] uma elaborada técnica de desmemória que alcançou toda a consciência social de uma região" (LINDOSO, 2005. p.25).

É a essa herança negativa do discurso historiográfico acerca dos segmentos marginalizados, nesse caso específico: o negro, que Lindoso chama de "esquecimento". Um esquecimento produzido por um discurso oficial comprometido com as classes dominantes, destacando fatos e heróis em uma história que tende a evidenciar a figura do vencedor. Aquele que detêm o poder determina a produção do discurso historiográfico, fazendo com que os oprimidos não apareçam ou, quando referenciado, seja na condição que Ulisses Rafael aponta em análise ao que ele chama de "quadra clássica da historiografia alagoana" para se referir à "Geografia Alagoana", 
de Tomaz do Bonfim Espíndola; "História de Alagoas", de Moreno Brandão; "História das Alagoas", de Craveiro Costa e, por fim, "História da civilização de Alagoas”, de Jaime de Altavilla. Da análise dessas obras e sobre a participação dos negros no Estado, Rafael (2004, p. 156) aponta:

Segundo esses estudiosos, a atuação daquele segmento serviu mais para o enaltecimento da ação dos detentores das prerrogativas senhoriais, do que para uma valorização da sua capacidade de participação no jogo político que se arma sempre que se confrontam forças antagônicas.

Nessa passagem fica evidente a ideia que ora aqui se defende, em que os negros são tratados apenas para legitimar a ação do dominador, ele enquanto sujeito histórico é mencionado “como mero acidente de percurso". Em que tudo o que está relacionado ao universo simbólico dos negros: a cultura, os costumes, a roupa, a língua, a religião, perde seu significado real e passa a ser visto apenas em função do outro (o colonizador).

Com base nessa história lacunar permeada por esse discurso do esquecimento, Rafael vai procurar analisar a presença do negro mediante indicações que os autores clássicos alagoanos fazem a ele, dando um panorama geral do que foi escrito sobre o negro alagoano. O autor em questão começa sua análise apontando a Geografia Alagoana como sendo a primeira obra que cita diretamente a presença do negro em Alagoas, ainda que na categoria de escravo. Aponta também o importante trabalho de Alfredo Brandão, “Os Negros na História de Alagoas”, como estudo que se debruça, de fato, sobre os negros, fazendo um pequeno resgate dessa obra. Aponta, ainda, a obra de Abelardo Duarte, em estudo sobre "O Folclore negro das Alagoas", "como campo privilegiado da atuação negra”. Cita também obras como “O Banguê nas Alagoas”, de Manoel Diégues Júnior, e “Contribuição à História do Açúcar em Alagoas”, de Moacir Sant'Ana, que, de alguma forma, fazem referência aos negros.

Entretanto, uma das partes mais ricas nessa pesquisa de RAFAEL (2004) são as referências feitas à obra de Félix Lima Júnior, "Maceió de Outrora", que faz um apanhado acerca dos costumes e hábitos da vida social da população maceioense, trazendo pequenas passagens sobre as mulheres negras no cenário cotidiano da cidade. Segundo Rafael, essa obra "torna-se indispensável a quem pretenda reconstruir alguns aspectos pitorescos, históricos e sociais da Maceió do começo do século XX”. A essa obra, some-se Histórias do "Velho Jaraguá", de Maya Pedrosa; "A filha do Barão" e “Traços e Troças”, atribuídas a Pedro Nolasco Maciel.

Diante disso, em análise a obra de Félix Lima Júnior, RAFAEL (2004) mostra como essa atitude de indiferença pode ser vista. O silêncio que se fez sobre O Quebra de Xangô em 1912 limitou os estudiosos, cronistas e historiadores da época a se concentrarem em certos aspectos pitorescos da vida social de Maceió que geralmente escondem outros mais significativos para dar conta de explicar as relações sociais da época. Essa é a crítica a ênfase que Lima Júnior dar as 
negras quituteiras da cidade com suas "roupas alvíssimas" e "saias rendadas" e "bem engomadas". Rafael fala de um enaltecimento lírico a esses aspectos que realçam as condições sociais dessas mulheres a fim de reconstruir, num esforço até saudosista, um tempo passado por meio de vagas lembranças.

Foi batendo na tecla do "esquecimento" do discurso historiográfico oficial denunciado por LINDOSO (2005) que RAFAEL (2004), ao tentar reconstruir o episódio do Quebra, teve que recorrer aos "únicos documentos disponíveis", os jornais mais significativos em circulação no Estado. Utilizando-os como fonte de pesquisa a fim de trazer a luz aquele que foi um dos mais cruéis atos de violência contra as religiões afro-brasileiras. Essa escassez de fontes faz com que Rafael procurasse esses jornais, tendo o cuidado de utilizar jornais situacionistas e oposicionistas a fim de contrapor as diferentes versões para os fatos relatados.

No texto "A operação historiográfica", OHARA (2013), refletindo o pensamento de Michel de Certeau, discorre sobre o ofício do historiador descrevendo as principais características desse trabalho. Diante disso, percebe-se que existe uma relação entre o historiador e o lugar de onde ele fala e do qual ele fala (OHARA 2013, 198) Isto é claro, não se dá sem certos limites, ou melhor, nos termos do próprio Certeau: há um enquadramento do objeto de análise em um sistema de referências utilizadas pelo historiador, pois seu fazer historiográfico nada mais é do que um "gesto de se recortar a experiência, estabelecendo um jogo de pertencimentos e de afastamentos" (CERTEAU apud OHARA 2013, 199). Sua fala se move em um campo específico, onde são estabelecidos diálogos e concepções, por meio do método, das questões a serem tratadas e dos interesses do pesquisador.

É nesse sentido que se verifica o caráter político da escrita da História, que implica escolhas e posicionamentos que condicionam à escrita. Nessa perspectiva a que se considerar não só lugar social de onde se fala, mas também as problematizações feitas pelo historiador de acordo com os interesses da pesquisa.

Diante dessa abordagem do fazer historiográfico concedido por Certeau, convém destacar que é da articulação do lugar social e do ofício do historiador que ele está falando. Nessa perspectiva de análise, a "operação historiográfica" se dá mediante as possibilidades e limites colocados por esse espaço da escrita e é aí que encontramos grande legitimidade teórica dentro da análise feita por Dirceu Lindoso ao discurso estamental da historiografia alagoana acerca dos cabanos.

O "espaço e a regra" como analogia ao espaço da escrita e a regra social que a condiciona, fornecido por Dirceu Lindoso na obra "A Utopia Armada", está diretamente articulada às problematizações feitas por Certeau acerca da "operação historiográfica". Este termo foi cunhado para dar conta de explicar o condicionamento da escrita sobre a Insurreição Cabana de 1832, que 
teve como atores sociais os pobres das Matas do Tombo Real, consolidando outra maneira de se pensar a insurreição Cabana, que foi um movimento duplamente contraditório, mas também foi uma insurreição popular antiescravista e antilatifundiária.

Dada a importância desse termo - o espaço e a regra - para compreender os limites da escrita, é que o tomamos emprestado de LINDOSO (2005) para entender a situação dos povos tradicionais na ausência de representação na cartografia oficial e na ausência da utilização da cartografia social como ferramenta para visibilizar os atores sociais do corpo social da cidade, que foram esquecidos e negados na geo-história oficial de grande parte do território brasileiro.

Tendo um respaldo teórico legítimo nesta última obra, julga-se necessário explicar alguns elementos importantes que dão subsídio para a análise que se pretende fazer. Entre os pontos mais centrais, destaca-se: o espaço e a regra da escrita, a condição de cárcere textual e a categoria do esquecimento, que serão, aqui, brevemente discutidos.

Para Lindoso, o discurso tradicional fundado por uma historiografia estamental tem um comprometimento ideológico com a dominação sesmeiro-escravista em uma história tradicional que se dirige "socialmente contra os dominados". Nessa perspectiva de História tradicional e reacionária, toda escrita comprometida com a manutenção do status quo tende a criminalizar os movimentos populares como uma realidade que foge à normalidade social, pois a participação do povo na história sempre foi vista como a participação das classes perigosas.

O discurso histórico estamental vê no status quo a premissa que regula a vida das sociedades, e tudo o que a contradiga se inscreve, automaticamente, no âmbito da marginalidade social e histórica. O discurso histórico estamental recicla constantemente as premissas que fundamentam a ideologia do poder, contando que esse poder seja o das classes dominantes (LINDOSO, 2005, p. 28).

Ao fazer a leitura do movimento cabano LINDOSO (2005), aponta que essa redução da escrita restauradora e estamental implicava na ampliação de outras versões fundada na oralidade guerrilheira. Entretanto, quando finda a guerra, há um desmantelamento dessa oralidade resistindo apenas seus resíduos. É aí que se abre o espaço do "esquecimento", do não-dito, do não-escrito. "Essa redução do poder da oralidade associada à reduzida escrita restauradora provocou uma descontinuidade na memória historiográfica, o que chamei anteriormente de "esquecimento"" (LINDOSO, 2005, p. 22), que vai gerar também uma "geografia do esquecimento".

Aquilo que foge à regra da ordem instituída deve ser omitido e/ou reduzido e a consequência disso para os cabanos foi a folclorização de sua oralidade, bem como a folclorização da história da cidade de Palmeira dos Índios, bem como um apagamento da presença dos povos indígenas e quilombolas da origem da história do lugar. Por esse motivo é que Lindoso afirma que o "esquecimento" significou o desmantelamento da oralidade cabana. Esse desmantelamento pode ser visto quando o autor em questão explica a redução semântica sofrida por alguns vocábulos dessa 
oralidade. O termo Mucambo, por exemplo, perdeu seu significado de esconderijo para ser simplificado a estilo arquitetônico e modo de vida das populações pobres. Essa perda de sentido semântico, forçada pelo discurso estamental, dificulta o entendimento de alguns fatos cabanos além de contribuir para o que o autor chama de empobrecimento compulsório.

[...] o desmantelamento do sistema de oralidade popular, depois da Cabanagem de 1832, significou a ampliação do espaço de "esquecimento" social e cultural, que representa, no campo da cultura, o empobrecimento compulsório das populações cabanas no plano social. Há, portanto, uma conjunção entre empobrecimento compulsório e esquecimento cultural (LINDOSO, 2005, p. 26).

Essa técnica de "esquecimento" significa não só o empobrecimento cultural dos segmentos marginalizados da sociedade, significa também um empobrecimento geo-historiográfico, em que o comprometimento da escrita estamental com as classes dominantes reflete também a dominação do texto. Pois, como já foi dito anteriormente, o espaço da escrita aponta o espaço do poder instituído e uma contraversão à ordem deve ser reprimida, sendo os heróis populares adjetivados de “criminosos", "bandidos". Esses heróis são submetidos ao juízo da historiografia estamental que lhes confere no plano da escrita, um cárcere textual, ou seja, um espaço gráfico presidiário dentro dos limites estabelecidos pela escrita tradicional.

Esse tipo de geo-historiografia se proclama neutra como se os fatos falassem por si só, se descolando do real, do vivido. A consequência disso, é que há uma naturalização da condição de fracasso dos dominados, que se reifica, nesse discurso, como uma "Lei Geral da História". Segundo Walter Benjamin, “a tradição do oprimido nos ensina que o 'estado de exceção' no qual vivemos é na verdade a regra geral". Precisamos construir um conceito de História que corresponda a essa verdade (BENJAMIN,1996, p. 226). Precisamos construir uma Geografia que dê conta da realidade em que coexistimos. A concepção de Geografia que temos hoje não nos dá resposta ao assombro que estamos vivendo no século XXI.

\section{A CIDADE, O LUGAR, O ÍNDIO E O NEGRO}

A apropriação do território que hoje forma o município de Palmeira dos Índios traz uma história de exclusão visível a qualquer olhar mais atento dirigido à sua formação territorial. Esta formação está mascarada pela romântica lenda indígena ${ }^{1}$ e pela destituição da Igreja Nossa Senhora do Rosário dos Pretos de sua função religiosa para ceder lugar ao Museu de usos e costumes da cidade, como também pelo isolamento e não sinalização do território da Comunidade Quilombola

\footnotetext{
${ }^{1}$ Conta a lenda da Fundação da Cidade que Txiliá (filha de um velho guerreiro cego) era prometida a Êtafé Cacique da tribo que esperava Txiliá atingir a puberdade para se unir a donzela, porém Txiliá amava em segredo um jovem da tribo de nome Tilixi, quando o Cacique descobre o amor dos dois, enciumado, os sentenciou Tilixi a morrer de fome e sede, Txiliá que um dia fora socorrer o homem amado, foi morte por uma flecha disparada pelo cacique Êtafé, no outro dia, no lugar ode os dois haviam morrida nasceu uma Palmeira, dando nome a cidade de Palmeira dos Índios.
} 
da Tabacaria dentro do município, não permitindo as pessoas perceberem a violência impetrada aos diferentes povos na formação do território palmeirense, o que torna os habitantes desta cidade desinformados sobre sua própria história, sua raiz, sua memória. A discussão de uma cartografia social do município como ferramenta metodológica de apropriação do território dentro dos currículos da disciplina de Geografia coloca no tempo presente questões cotidianas que contribuirão para uma visão com uma maior proximidade do real da cartografia da cidade, como também de dar visibilidade aos diferentes povos que constituem o tecido social da cidade de Palmeira dos Índios. É preciso entender que uma invisibilidade cartográfica é, antes de tudo, reflexo de uma invisibilidade sociológica e jurídica de determinados segmentos da população da sociedade.

O Povo indígena Xukuru-Kariri e os quilombolas da Tabacaria têm juntado a sua história de vida à própria história da cidade. A cidade que antes de tudo é uma criação humana e deve acolher em seu interior todos os grupos que a ajudaram a construir, isto visto dentro de uma concepção democrática do que seria uma cidade. CARLOS (2007), em seu livro sobre "O lugar no/do mundo", chama a atenção de como é no lugar que se revela, se lê, se percebe, se entende o mundo moderno em suas múltiplas dimensões, numa perspectiva mais ampla, é no "lugar que se vive o cotidiano e é aí que ganha expressão o mundial. O mundial que existe no local, redefinindo seu conteúdo sem anular as particularidades" (CARLOS, 2007, p. 14).

Em Carlos (2007, p. 14) temos que

A sociedade urbana que, hoje, se produz em parte de modo real e concreto, em parte de modo virtual e possível, constitui-se enquanto mundialidade, apresentando tendência à homogeneização, ao mesmo tempo em que permite a diferenciação. O lugar permite pensar a articulação do local com o espaço urbano que se manifesta como horizonte. O lugar abre a perspectiva para se pensar o viver e o habitar, o uso e o consumo, os processos de apropriação do espaço. As relações que os indivíduos mantêm com os espaços habitados se exprimem todos os dias nos modos do uso, nas condições mais banais, no secundário, no acidental. É o espaço passível de ser sentido, pensado, apropriado e vivido através do corpo (Ibidem).

O homem percebe o mundo por meio de seu corpo, de seus sentidos, que ele constrói e se apropria do espaço e do mundo; sendo o lugar a porção do espaço apropriável para a vida apropriada mediante o corpo — os sentidos — os passos de seus moradores, é o bairro, é a praça, é a rua (CARLOS, 2007). A tríade cidadão-identidade-lugar aponta a necessidade de considerar o corpo, pois é por meio dele que o homem habita e se apropria do espaço (por meio dos modos de uso). A nossa existência tem uma corporeidade, pois agimos mediante o corpo. Ele nos dá acesso ao mundo, é o nó vital, imediato visto pela sociedade como fonte e suporte de toda cultura. (CARLOS, 2007: p.14-19).

Então cabe aqui perguntar como se encontram estes corpos indígenas e negros na cidade de Palmeira dos Índios? Onde estão? Como andam? O que comem? Como dormem? Como eles usam 
a cidade e são usados por ela? A cidade os reconhece como seus filhos? Ou eles são estrangeiros em seu próprio lugar? Como estão representados na cidade? Quais os equipamentos que testificam de sua presença dentro do espaço habitado?

A cidade é para os povos indígenas e negros que aí vivem ou sobrevivem, o território de seus ancestrais, o locus de sua vivência, de sua reprodução enquanto índios e negros. Nesta emergência as novas territorialidades na cidade Palmeira dos Índios se desvelam e mostram como sobrevive o povo que a ajudou a se erguer enquanto cidade: negros, índios e brancos na clivagem pelo direito à cidade e a seus pretensos benefícios.

É no território que as desigualdades sociais tornam-se evidentes entre os cidadãos, as condições de vida entre os moradores de uma mesma cidade mostram-se diferenciadas, a presença/ausência dos serviços públicos se faz sentir e a qualidade destes mesmos serviços apresenta-se desiguais dessa forma: "O direito a ter direitos é expresso ou negado, abnegado ou reivindicado a partir de lugares concretos: o morar, o estudar, o trabalhar, o divertir-se, o viver saudavelmente, o transitar, o opinar, o participar" (KOGA 2011, 33)

No bojo destas considerações, aponta-se a problemática da visibilidade cartográfica dos povos tradicionais na cidade consequentemente como são discutidas essas temáticas dentro dos conteúdos do ensino da Geografia. Como estão espraiadas as territorialidades negras e indígenas no território palmeirense e se temos essas discussões refletidas nos conteúdos curriculares do ensino da Geografia.

Como a cidade de Palmeira dos Índios entende esta questão? Como nestas fronteiras invisíveis estão postas? Estas questões de identidade e alteridade tão decantada por aqueles que lidam com a temática (FUNAI, MDA, MINC, etc.). Como elas estão postas no currículo das diferentes disciplinas que abordam a temática e estudo. Como estamos fazendo a discussão do lugar e quais os instrumentos possíveis de serem utilizados na leitura e compreensão da cidade?

\section{A CARTOGRAFIA SOCIAL (CS) COMO FERRAMENTA DE LEITURA DA ESPACIALIDADE DOS POVOS TRADICIONAIS NA CONFIGURAÇÃO DA CIDADE}

A cartografia social é vista como um processo de construção coletiva que aproxima, em uma mesma categoria de importância, pesquisadores e agentes sociais mapeados (SANTOS 2016, 274). A Cartografia social prima por fazer do mapeamento uma construção coletiva, em que todos os atores envolvidos no território participam de maneira horizontalizada.

Como um instrumento pedagógico de fixação de conteúdo, na CS os alunos são peças fundamentais. São informantes do tema a ser mapeado e construtores desse mesmo mapa. A CS tem uma preocupação com o conteúdo, ao invés da forma como o faz a cartografia oficial. 
Para tanto, é necessário pensarmos os grupos discentes enquanto protagonistas da construção de seu próprio conhecimento. O envolvimento dos estudantes é uma peça fundamental no processo, já que devem ser inseridos como partícipes do ato de construção do mapa, e não como simples operacionalizadores das novas tecnologias digitais. Dessa forma, assumem um papel de seres pensantes e reflexivos sobre sua própria realidade e sobre a realidade de seus grupos (SANTOS, 2016, p. 275).

As condições de possibilidades metodológicas enquanto prática pedagógica da CS são inúmeras, ela abre possibilidade também para a interpretação de dados e ferramentas oficiais (georreferenciamento) com uma leitura dialética do território ou lugar. Sabe-se que a CS é uma metodologia participativa, tendo suas raízes nos movimentos sociais, ONG's, pesquisas sociais, etc.

Em Gomes, ele afirma que a CS

É a concepção da linguagem cartográfica (com privilégio da significação em detrimento da forma em si mesma) associada à metodologia participativa e dialógica que aproxima a CS das práticas escolares. Experiências com crianças e jovens escolares de comunidades tradicionais, com jovens em escolas urbanas que se encontram em situação de risco social e, ou, econômico, bem como em projetos de educação ambiental, têm demonstrado o potencial para a formação, para a cidadania e à construção de conceitos geográficos, como lugar/território e territorialidade (GOMES, 2017. p. 3).

Gomes (2017) afirma que é na CS que acontece a troca entre sujeitos sociais, pesquisadores e técnico, sendo, por excelência, um espaço formador em que, na troca horizontal de saberes, a metodologia qualitativa é utilizada em detrimento da metodologia quantitativa. Convém ressaltar que esse enrijecimento na visão da utilização de metodologia quantitativa no levantamento de dados sobre um determinado lugar é questionável porque são inúmeras as experiências em que as interpretações de dados foram feitas utilizando a metodologia de análise dialética, com pesquisa quantitativa e os resultados, foram coerentes com a realidade apresentada.

Nos gráficos, tabelas e mapas abaixo, temos uma demonstração de utilização de dados georreferenciados retirados do censo demográfico do Instituto Brasileiro de Geografia e Estatística (IBGE) de 2018 sobre a Cidade de Palmeira dos Índios.

Tabela 1- Alagoas.

\begin{tabular}{ccccc}
\cline { 2 - 5 } & \multicolumn{2}{c}{ Alagoas } & \multicolumn{2}{c}{ Palmeira dos Índios } \\
\hline Pardos & 1.875 .794 & $60,2 \%$ & 40.683 & $57,8 \%$ \\
Brancos & 984.955 & $31,6 \%$ & 23.855 & $33,9 \%$ \\
Pretos & 204.852 & $6,6 \%$ & 3.706 & $5,3 \%$ \\
Indígenas & 14.497 & $0,5 \%$ & 1.676 & $2,4 \%$ \\
Amarelos & 36.658 & $1,2 \%$ & 448 & $0,6 \%$ \\
Total & 3116756 & $100,0 \%$ & 70368 & $100,0 \%$ \\
\hline
\end{tabular}

Fonte. IBGE. 2018.Elaborado por Odair B. Moraes. 


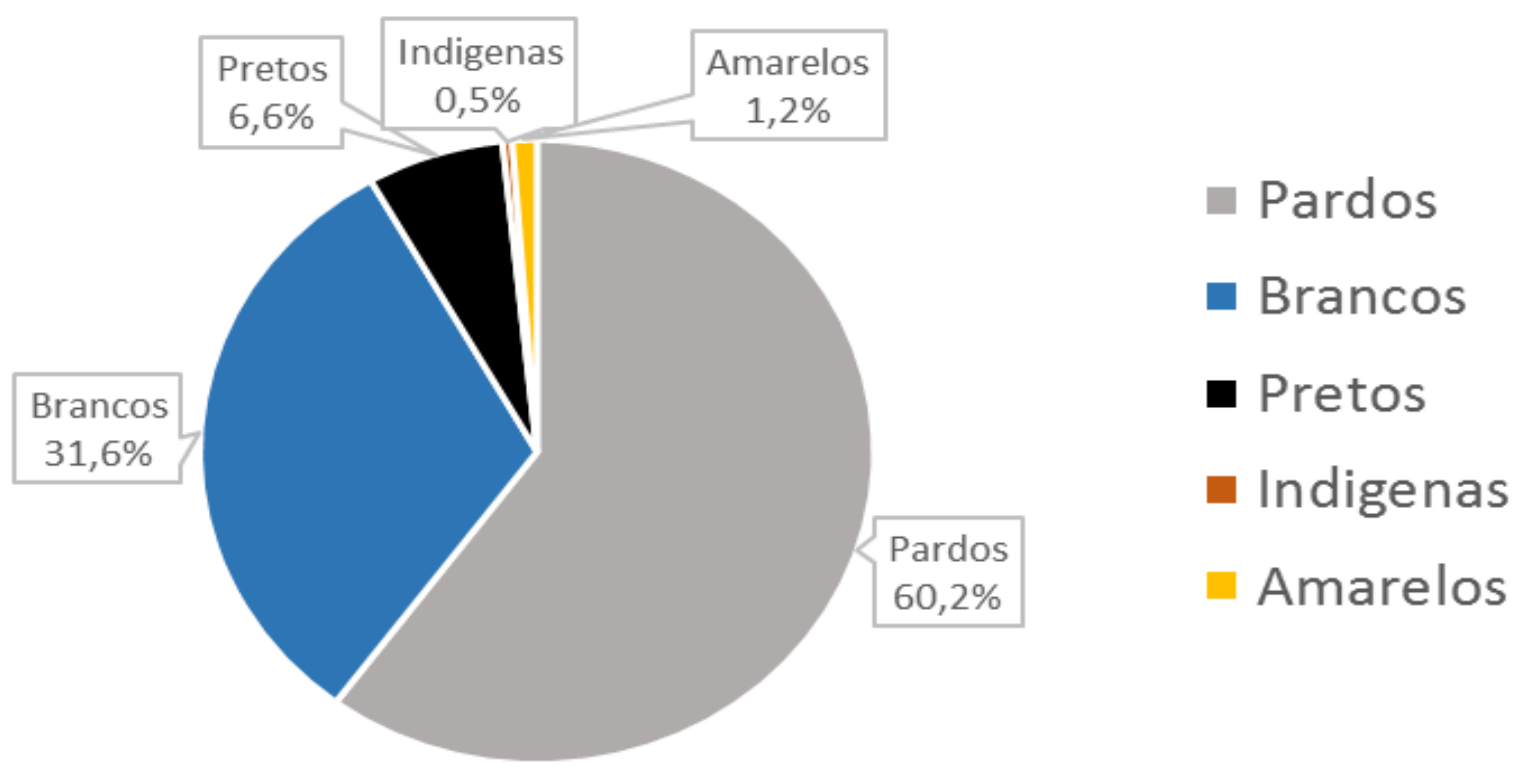

Figura 1 - Palmeira dos Índios.

Fonte: IBGE. 2018.Elaborado por Odair Barbosa de Moraes.

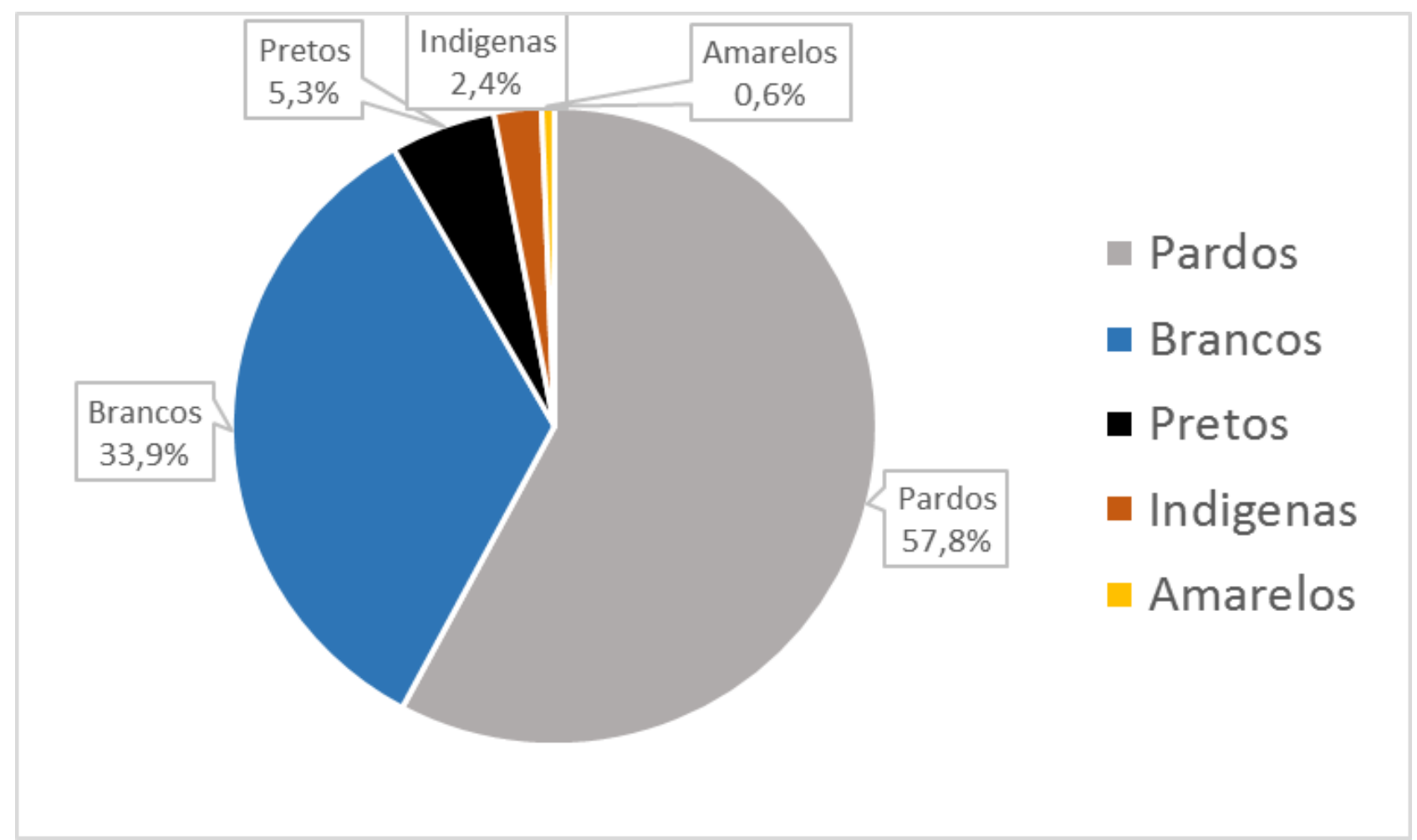

Figura 2 - Palmeira dos Índios.

Fonte: IBGE. 2018.Elaborado por Odair Barbosa de Moraes. 


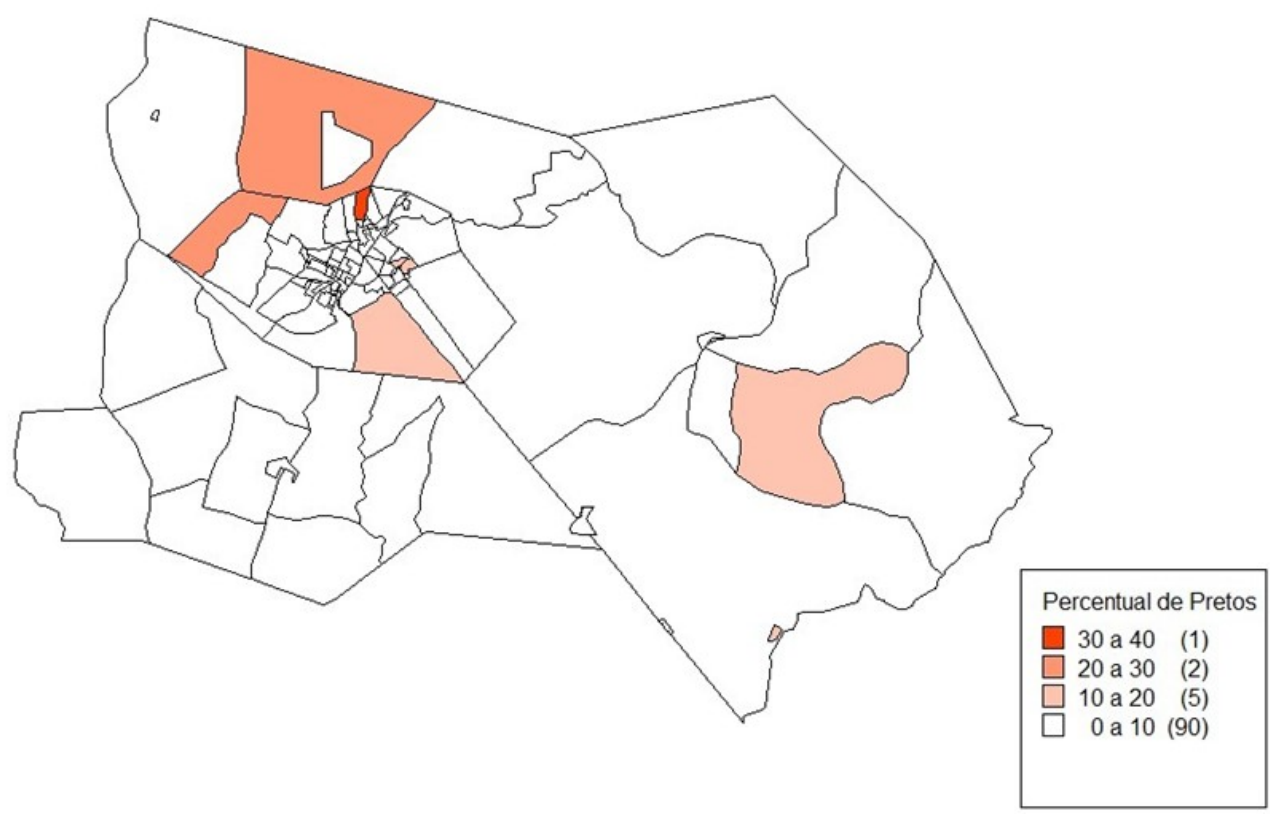

Figura 3 - Palmeira dos Índios.

Elaborado por: Odair Barbosa de Moraes.

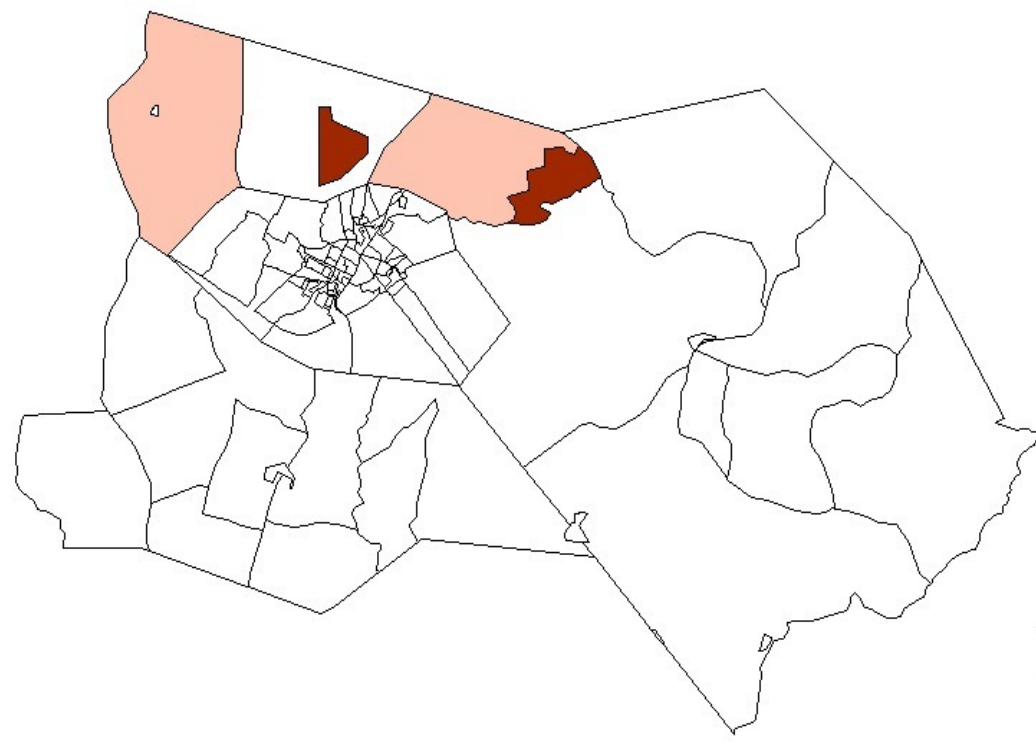

Percentual de Indigenas

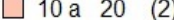

$\square \quad 0$ a $10(94)$

Figura 4 - Palmeira dos Índios.

Elaborado por: Odair Barbosa de Moraes. 


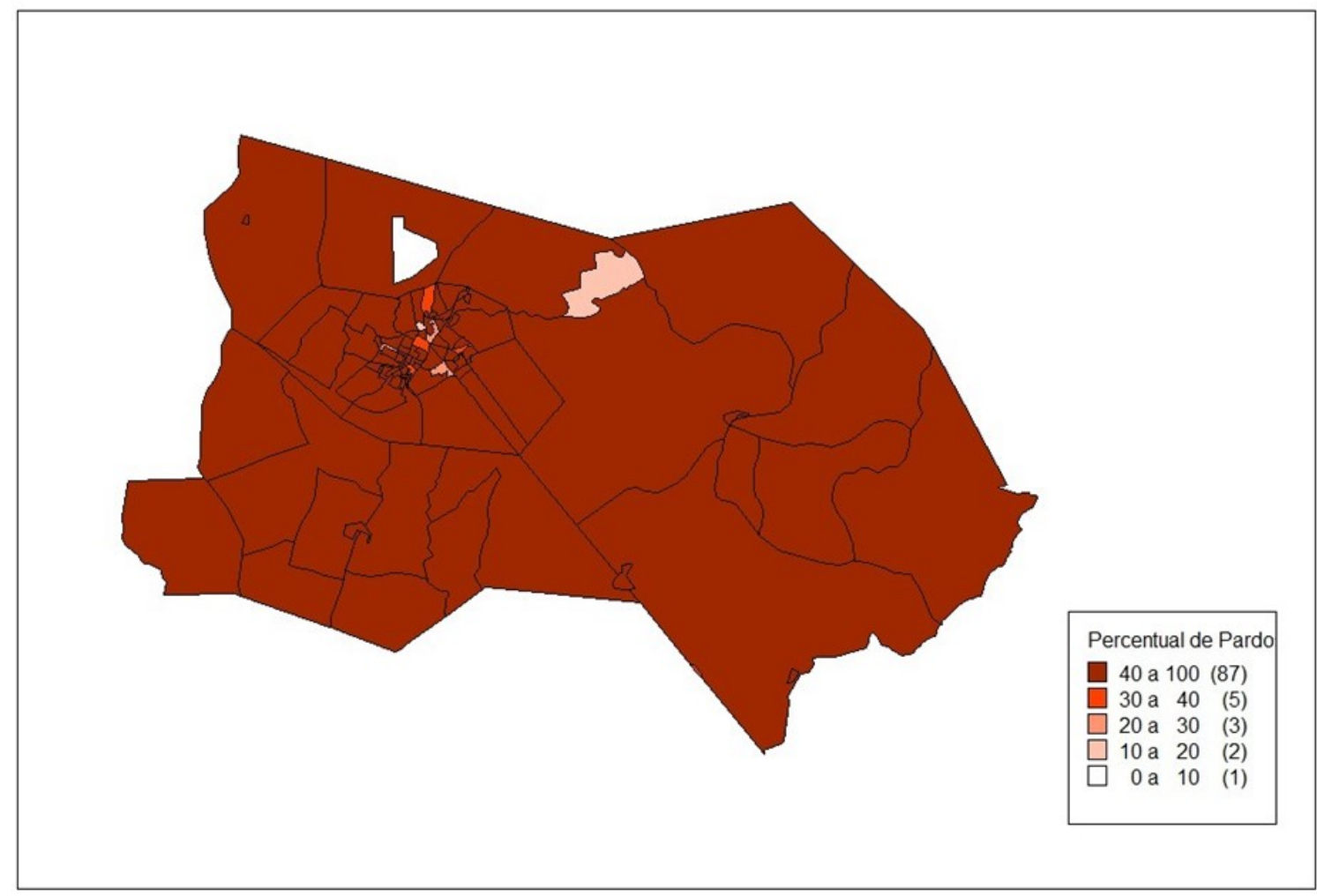

Figura 5 - Palmeira dos Índios.

Elaborado por: Odair Barbosa de Moraes.

Esses dados oficiais, organizados e sobreposto sobre o Município de Palmeira dos Índios, não diriam nada acerca da cidade para o visitante ou o morador desatento e desinformado da geohistória de sua cidade. Aqueles que conhecem a cidade olhando os mapas e desenhos verão que existe uma negação da identidade indígena e quilombola dentro do município, pois o percentual de pardos é altíssimo (ver figura 5). Em relação a presença indígena, estão localizados nas franjas da cidade. Estão fora dela. São periféricos. (Ver figura 4). Os negros são os que têm o menor percentual (ver figura 3), localizados juntamente na periferia da cidade nos bairros mais afastados do centro e em um percentual reduzido, teremos uma concentração maior na região da Tabacaria (onde se localiza a referida Comunidade Quilombola da Tabacaria).

Vistos dessa maneira esses dados parecem frios e distantes do cotidiano do aluno. Se tivermos a oportunidade de, identificando os bairros, estabelecendo vínculos com os alunos, teremos um outro olhar sobre essa informação. Um detalhe precioso é que o censo do IBGE ainda não adaptou seu questionário à presença da identidade quilombola no município. Declarar-se quilombola não é a mesma coisa que declarar-se negro. A depender do nível de formação e de informação do sujeito envolvido, a identidade quilombola é bem-vinda, mas a cor negra não o é. São questões muito complexas que envolve toda a processualidade da construção da identidade quilombola que não teremos espaço para discutir aqui nesse texto. O que temos é antes de tudo um reflexo da não adequação dos questionários censitários as realidades pesquisadas. O que se percebe 
é que a visão eurocêntrica permeia os mais diferentes campos de organização da informação no país, fortalecendo o olhar que Dirceu Lindoso nos fez refletir sobre a "categoria do esquecimento" dentro da construção dos discursos e representações da Geografia e da História do Brasil.

Se aplicamos os pressupostos da Cartografia Social, fazendo uma releitura dinâmica e atualizada juntamente com os alunos em salas de aulas, redesenhando toda a estrutura étnica da cidade, certamente teríamos a revelação de uma outra cartografia. Uma cartografia muitas vezes silenciada, esquecida e enrijecida pelo preconceito e negação daqueles que fazem parte da cidade, teríamos uma cartografia dos vencidos, uma cartografia cotidiana, uma cartografia real, uma cidade real.

\section{CONCLUSÃO}

A cidade é uma construção humana. Revela na sua essência toda processualidade da sociedade. Fazer uma geografia dos vencidos, uma geografia em que os esquecidos e silenciados da história da cidade sejam representados é educar para a vida. A Cartografia Social é uma postura dialógica entre professor-aluno e sociedade. Procurar uma outra Geografia escolar que não a dos livros oficiais é ousar para a transformação da realidade. A Geografia do lembrar deve se sobrepor a técnica de "esquecimento", significa compreender que a técnica do esquecimento nos leva, não só ao empobrecimento cultural dos segmentos marginalizados da sociedade, significa também a um empobrecimento geo-historiográfico, em que o comprometimento da escrita estamental com as classes dominantes reflete também a dominação do texto, a dominação dos mapas, a dominação da Geografia. Os povos negados (Lindoso 2005) na cidade, por meio da Cartografia Social serão visibilizados, discutidos, escolhidos, enfim, cartografados. Na cidade de Palmeira dos Índios, os moradores e visitantes desconhecem a localização do Quilombo da Tabacaria. O poder estamental destitui a Igreja de Nossa Senhora do Rosário dos Pretos e cria um museu de costumes onde esse museu não cumpre sua função de maneira inteligente. Onde, nesse museu, na sua entrada, estão postos dois manequins negros com alcunhas de "ladrão" e "fujão". Pois, como já foi dito por Dirceu Lindoso, "o espaço da escrita aponta o espaço do poder instituído e uma contraversão à ordem deve ser reprimida, sendo os heróis populares adjetivados de 'criminosos', 'bandidos"'. Esses heróis são submetidos ao juízo da historiografia estamental que lhes confere no plano da escrita, um cárcere textual, ou seja, um espaço gráfico presidiário dentro dos limites estabelecidos pela escrita tradicional. A Cartografia como também a Geografia que se utiliza dessa mesma escrita reproduz uma Geografia de guerra, de vencedores, em que o homem simples não tem lugar para escrever as suas geografias. 


\section{REFERÊNCIAS}

BENJAMIM, W. Magia e Técnica, arte e política: ensaios sobre literatura e história da cultura. 7. ed. São Paulo: Brasiliense, 1994. 272p.

KOGA, D. Medidas de cidades: entre territórios de vida e territorios vividos. 1. ed. São Paulo: Cortez, 2011. 336p.

LINDOSO, D. A Utopia Armada. 2. ed. Maceió, Alagoas: Edufal, 2005. 408p.

HABEGGER, S.; MANCILA, I. El poder de la Cartografía Social en las prácticas contrahegemónicas o La Cartografía Social como estrategia para diagnosticar nuestro território. (2006) Disponível em: <http://acervo.paulofreire.org:8080/jspui/bitstream /7891/4034/1/FPF_PTPF_01_0693.pdf >. Acesso em: 10 jun. 2020.

SANTOS, D. Cartografia Social: O estudo da cartografia social como perspectiva contemporânea da Geografia. Interespaço: Revista de Geografia e Interdisciplinaridade, São Luís, v. 2. n. 6, p. 273-293, 2016.

OHARA, J. R. M. Considerações sobre "História e Estrutura" e Passado histórico, presente historiográfico: de Certeau, Michel. História da Historiografia, Ouro Preto, n. 12, p. 197-212, 2013.

RAFAEL, U. N. Xangô Rezado Baixo: um estudo da Perseguição aos Terreiros de Alagoas em 1912. 2004. 266 f. Tese (Doutorado em Sociologia e Antropologia) - Instituto de Filosofia e Ciências Sociais, Universidade Federal do Rio de Janeiro, Rio de Janeiro, 2004.

GOMES, M. F. V. B. Cartografia Social e Geografia Escolar: aproximações e possibilidades. Revista Brasileira de Educação em Geografia, v. 7, n. 13, p. 97-110, 2017.

CARVAlHO, J. I. F.; SANTOS, F. K. S.; SOUSA, L. A. A Cartografia Social e o Ensino de Geografia na Educação básica: um desenho a construir. Revista de Ensino de Geografia, Uberlândia, v. 8, n. 15, p. 82-97, 2017. 